\title{
Industrially relevant hydrolyzability and fermentability of sugarcane bagasse improved effectively by glycerol organosolv pretreatment
}

Fubao Fuelbiol Sun ${ }^{1 *}$, Xiaoqin Zhao ${ }^{1,2}$, Jiapeng Hong ${ }^{1,3}$, Yanjun Tang ${ }^{3}$, Liang Wang ${ }^{1,4}$, Haiyan Sun ${ }^{5}$, Xiang Li ${ }^{1}$ and Jinguang $\mathrm{Hu}^{6}$

\begin{abstract}
Background: Previous work has demonstrated that glycerol organosolv pretreatment can effectively improve the hydrolyzability of various lignocellulosic substrates. This pretreatment process strategy is ideal to integrate a commercially successful lignocellulosic and vegetable oil biorefinery industry. However, industrially relevant high-solid-loading hydrolyzability and fermentability of the pretreated substrates have yet to be considered for enzyme-based lignocellulosic biorefineries.

Results: In this study, an AGO pretreatment of sugarcane bagasse was evaluated with regard to the component selectivity, structural modification, hydrolyzability, and fermentation of pretreated substrates. The results showed that the AGO pretreatment presented good component selectivity, removing approximately $70 \%$ lignin and hemicellulose, respectively, from sugarcane bagasse with a near-intact preservation ( $94 \%$ ) of the overall cellulose. The pretreatment deconstructed the recalcitrant architecture of natural lignocellulosic biomass, thereby modifying the structure at the macro-/micrometer level (fiber size, surface area, average size, roughness) and supermolecular level (key chemical bond dissociation) of lignocellulosic substrates towards good hydrolyzability. Notably, extraordinarily few fermentation inhibitors ( $<0.2 \mathrm{~g}$ furfural and 5-hydromethyl furfural $/ \mathrm{kg}$ feedstock) were generated from the AGO pretreatment process, which was apparently due to the prominent role of glycerol organic solvent in protecting monosaccharides against further degradation. The 72-h enzymatic hydrolysis of pretreated substrates at $15 \%$ solid content achieved $90 \%$ completion with Cellic CTec2 at $10 \mathrm{FPU} / \mathrm{g}$ dried substrate. With a simple nutrition (only $10 \mathrm{~g} / \mathrm{L}\left(\mathrm{NH}_{4}\right)_{2} \mathrm{SO}_{4}$ ) addition, the fed-batch semi-SSF of AGO-pretreated substrates (30\% solid content) almost reached $50 \mathrm{~g} / \mathrm{L}$ ethanol with cellulase preparation at $10 \mathrm{FPU} / \mathrm{g}$ dried substrate. These results have revealed that the pretreated substrate is susceptible and accessible to cellulase enzymes, thereafter exhibiting remarkable hydrolyzability and fermentability.
\end{abstract}

Conclusion: The AGO pretreatment is a promising candidate for the current pretreatment process towards industrially relevant enzyme-based lignocellulosic biorefineries.

Keywords: Atmospheric glycerol organosolv pretreatment, Sugarcane bagasse, Structural feature, Furfural and 5-hydromethyl furfural, Enzymatic hydrolysis, Ethanol fermentation

\footnotetext{
*Correspondence: fubaosun@jiangnan.edu.cn; sunfubao@hotmail.com

${ }^{1}$ Key Laboratory of Industrial Biotechnology, School of Biotechnology,

Ministry of Education, Jiangnan University, Wuxi 214122, China

Full list of author information is available at the end of the article
} 


\section{Background}

The transition from a conventional oil refinery to a "biorefinery" based on renewable lignocellulosic biomass is crucial if we are to move to a more environmentally friendly economy [1]. To make bio-based products more cost competitive with fossil-derived conventional commodities, an efficient pretreatment strategy is needed to first open up/disrupt the complex plant cell wall structure, which allows the "cellulase" enzymes to access and deconstruct the polysaccharides within the biomass into a monomeric sugar platform [2]. Although numerous potential pretreatment strategies such as dilute acid/alkaline pretreatment, steam explosion, ammonia fiber explosion (AFEX), sulfite pretreatment to overcome recalcitrance of lignocellulose (SPORL), and ionic liquid and liquid hot water pretreatment have been extensively studied, these current pretreatment techniques still pose various challenges, especially in terms of excess water use and expensive chemicals and fermentation inhibitors [3-8].

Organosolv pretreatment, in contrast, has attracted significant attention owing to the efficiency of fractionating the biomass components and the potential of scaleup in the commercially relevant biorefinery process [9-12]. However, the low-boiling-point organic solvents used in the pretreatment process have restricted the process development because of the high-pressure operation and their high volatility and flammability. In addition, the cost of these solvents is usually too high to be industrially feasible. Therefore, it is crucial to identify a high-boilingpoint organic solvent with a low price for the development of an efficient organosolv pretreatment process.

Glycerol, a high-boiling-point organic solvent derived from the oleochemical industry as a by-product has become very attractive. Recently, with the increasingly flourishing biodiesel production, it is envisioned that the glycerol market will become oversupplied in the near future [13]. In this context, an atmospheric glycerol organosolv (AGO) pretreatment, using industrial glycerol derived from the oleochemical industry, was initiated in our lab $[14,15]$. The AGO pretreatment removed $>65 \%$ lignin and $>80 \%$ hemicellulose while keeping cellulose (>95\%) almost intact at the level initially assessed on the wheat straw, and the AGO-pretreated wheat straw was efficiently hydrolyzed ( $>90 \%$ cellulose conversion) after $24 \mathrm{~h}$. Since then, numerous research groups have tested glycerol-based organosolv pretreatment on various lignocellulosic biomass. Martin et al. [16] studied the effect of glycerol pretreatment on the main components of sugarcane bagasse, showing that the glycerol acted more selectively on lignin than on xylan. Moreover, the cellulose was almost completely recovered in the pretreated solids, accounting for $72 \%\left(\mathrm{~g} \mathrm{~g}^{-1}\right)$ of the pretreated substrate. Novo et al. [17] showed that the glycerol pretreatment attained good cellulose preservation ( $>91 \%)$ and lignin removal $(80 \%)$. Zhang et al. [18] reported that $>96 \%$ of the cellulose was recovered, whereas the lignin and hemicellulose removal was almost 60 and $80 \%$, respectively, with an acid-catalyzed glycerol organosolv pretreatment. Romaní et al. [19] found that aqueous glycerol pretreatment removed 72 \% lignin from the Eucalyptus globulus wood and preserved an unprecedentedly high cellulose content (83\%, corresponding to $98 \%$ of the original) in the pretreated substrate. Moreover, the pretreated substrate presented $98 \%$ of 48-h enzymatic hydrolysis with 20 filter paper units (FPU) of Celluclast $1.5 \mathrm{~L}$ and $100 \mathrm{IU}$ of Novozyme 188 of each gram substrate. Hundt et al. [20] realized almost complete enzymatic hydrolysis of the alkaline glycerol-pretreated wood with an enzyme loading of $15 \mathrm{FPU} / \mathrm{g}$ Cellulase (Celluclast $1.5 \mathrm{~L}$ ) and $30 \mathrm{CBU} / \mathrm{g}$ $\beta$-glucosidase (Novozyme 188). Briefly, glycerol is an excellent solvent for organosolv pretreatment. Glycerol organosolv pretreatment has outstanding selectivity in a range of various natural lignocellulosic substrates, thereby effectively improving the hydrolyzability of lignocellulosic substrates [21].

However, most of the present literature has evaluated the substrate hydrolyzability at a very low $(<5 \%)$ solid content, which is far from the industrially relevant enzyme-based lignocellulosic biorefinery process [12]. Furthermore, there is currently very little information on the microbial fermentation of glycerol organosolvpretreated substrates. Accordingly, the objective of this study is to investigate the effect of AGO pretreatment on the composition and structure of sugarcane bagasse with various modern analytical methods, i.e., scanning electron microscopy (SEM), atomic force microscopy (AFM), confocal laser scanning microscopy (CLSM), thermogravimetric analysis (TGA), and Fourier transform infrared spectroscopy (FT-IR). The hydrolyzability of pretreated substrates at a high consistency (>10 \%) was then assessed with a new commercial cellulase preparation Cellic CTec 2 at a relatively low enzyme loading (6 and $10 \mathrm{FPU} / \mathrm{g}$ dried substrate) to correlate its susceptibility with the commercially successful enzymatic saccharification process. Finally, a high-gravity mash ethanol fermentation was carried out with simultaneous saccharification and fermentation (SSF), SSF with prehydrolysis (semi-SSF), and fed-batch semi-SSF to describe the fermentability of AGO-pretreated substrates. Additionally, key fermentation inhibitory compounds that have been often reported were also detected, followed by a mass balance analysis.

\section{Results and discussion}

In our initial work, the AGO pretreatment of wheat straw was performed in a $70 \%$ glycerol liquor at $220{ }^{\circ} \mathrm{C}$ 
of cooking temperature and $3 \mathrm{~h}$ of holding time with a preliminary selection [15]. With respect to the feedstock variance, therefore, it is necessary to choose some key parameters for the sugarcane bagasse.

\section{Preliminary selection of pretreatment condition Pretreatment temperature}

In this work, each $10 \mathrm{~g}$ of dried sugarcane bagasse was cooked at different temperatures for $2 \mathrm{~h}$ in $200 \mathrm{~g}, 70 \%$ aqueous glycerol liquor. The pretreatment yields and main chemical components of the sugarcane bagasse are shown in Fig. 1. With the pretreatment temperature increasing from 200 to $240{ }^{\circ} \mathrm{C}$, the pretreatment yield decreased significantly from 68 to $57 \%$, and the original cellulose also degraded marginally, deceasing from 96 (210) to $91 \%$ $\left(240{ }^{\circ} \mathrm{C}\right)$. When the pretreatment temperature was lower than $220{ }^{\circ} \mathrm{C}$, lignin and hemicellulose degraded sharply from the sugarcane bagasse with the increase in pretreatment temperature. At $220{ }^{\circ} \mathrm{C}$, the residual lignin and hemicellulose in the pretreated substrate remained at 33 and $29 \%$, respectively, of the original content. With a pretreatment temperature higher than $220^{\circ} \mathrm{C}$, the lignin and hemicellulose content remained almost unchanged. These results are very similar to those obtained for wheat straw in our earlier work [16]. Therefore, it is adequate to select $220^{\circ} \mathrm{C}$ as the reaction temperature for the AGO pretreatment of sugarcane bagasse.

\section{Pretreatment time}

Figure 2 shows some effects of pretreatment time on the main components of sugarcane bagasse. With the AGO

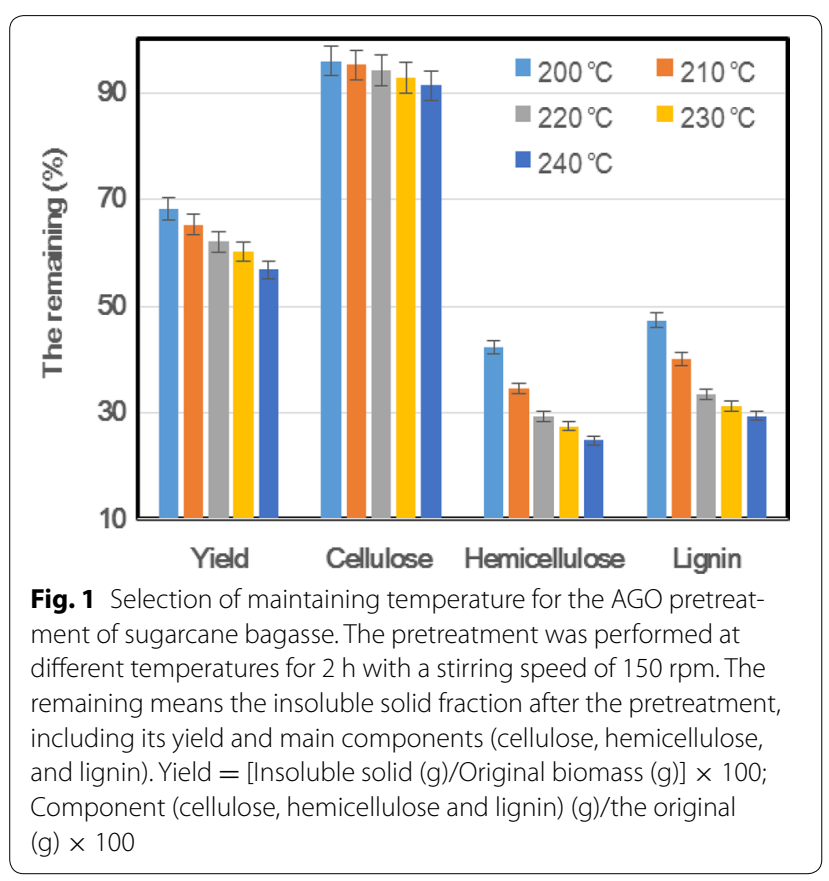

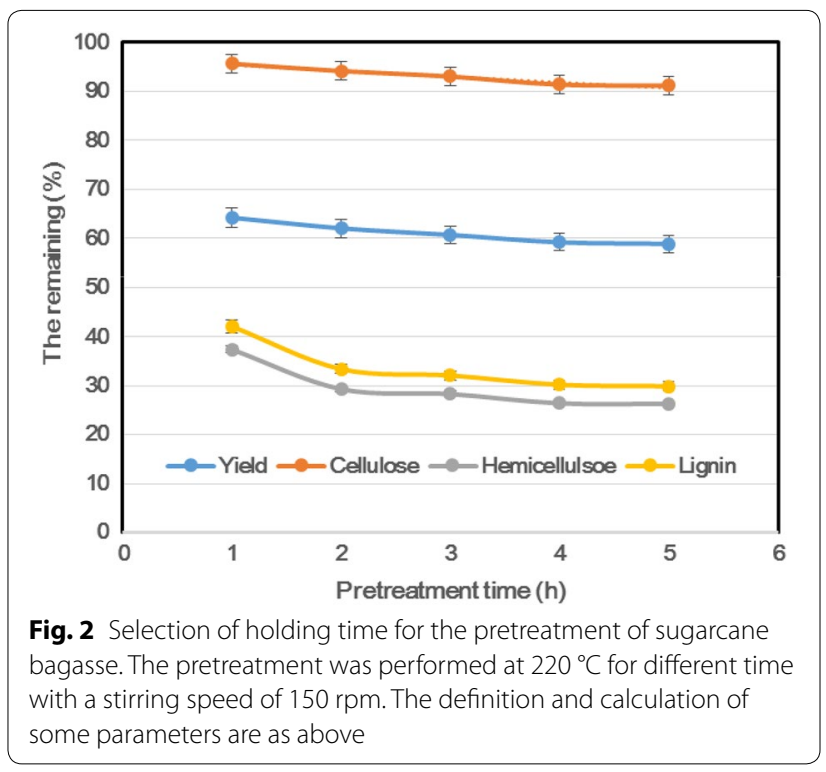

pretreatment at $220{ }^{\circ} \mathrm{C}$ from 1 to $5 \mathrm{~h}$, the pretreatment yield decreased from 64 to $59 \%$, and the cellulose content decreased slightly from 96 (1) to $91 \%$ (5 h). With the prolonged pretreatment time, there was a large change in hemicellulose and lignin removal. When the pretreatment time was shorter than $2 \mathrm{~h}$, the lignin and hemicellulose were removed significantly from the sugarcane bagasse. At $2 \mathrm{~h}$, the removal of lignin and hemicellulose reached 67 and $71 \%$, respectively. Thereafter, the hemicellulose and lignin remaining in the pretreated substrates were almost stable with the extended pretreatment time. Therefore, it is favorable to choose $2 \mathrm{~h}$ as a desirable holding time for the AGO pretreatment.

With the foregoing preliminary selection, the AGO pretreatment of sugarcane bagasse should be performed at $220{ }^{\circ} \mathrm{C}$ for $2 \mathrm{~h}$ in a $70 \%$ glycerol liquor, which is very similar to that obtained for wheat straw [15]. The pretreatment removed approximately $70 \%$ of the lignin and hemicellulose from sugarcane bagasse while maintaining the overall cellulose $(94 \%)$ almost intact. That is, the pretreated substrate had a cellulose purity of $60 \%$, mingled with a small amount of hemicellulose (13\%) and lignin (14\%). The result is consistent with the recent work summarized by our coworkers [21]. Such a high cellulose content in pretreated substrates is very attractive for ongoing industrially relevant high-titer bioethanol production.

\section{Structural features}

The foregoing AGO pretreatment technique possesses a remarkable qualification for the selection of components for natural lignocellulosic feedstock. It is interesting to feature the impact of this selection on lignocellulosic architecture. Recently, a few researchers have argued 
in their work on some leading pretreatments that some chemical components (lignin, hemicellulose, and acetyl group), physical properties (average size, surface area, roughness, and component redistribution), and supermolecular structures (key chemical bonds, functional groups) of the lignocellulosic biomass should be used to represent the substrate's inherent recalcitrance to enzymatic hydrolysis [22, 23]. Accordingly, it is presumable that the AGO pretreatment should deconstruct and modify the architecture of the lignocellulosic substrate. To verify this presumption, structural features in these properties of sugarcane bagasse before and after AGO pretreatment are characterized with a series of modern analytical equipment.

\section{Multi-scale visualization}

\section{TGA}

A TGA of the sugarcane bagasse before and after AGO pretreatment was made, as shown in Fig. 3. The original sugarcane bagasse began to degrade approximately at $217{ }^{\circ} \mathrm{C}$, and degraded $20 \%$ at $282{ }^{\circ} \mathrm{C}$ and $50 \%$ at $331{ }^{\circ} \mathrm{C}$. Relatively, the pretreated sample started the decomposition at about $238{ }^{\circ} \mathrm{C}$, which decomposed $20 \%$ at $324{ }^{\circ} \mathrm{C}$ and $50 \%$ at $348{ }^{\circ} \mathrm{C}$. This indicates that the AGO-pretreated sugarcane bagasse had a high degradation temperature and a high thermal stability, which is attributed to partial removal of hemicellulose and lignin. Additionally, after being heated to $530{ }^{\circ} \mathrm{C}$, both of two sugarcane bagasse samples had a different weight of some residues. The residual of AGO-pretreated substrate weighed $6.9 \%$, significantly less than that $(11.3 \%)$ of the original. This indicated that some lignin and other sources of ash were also removed from the sugarcane bagasse after the

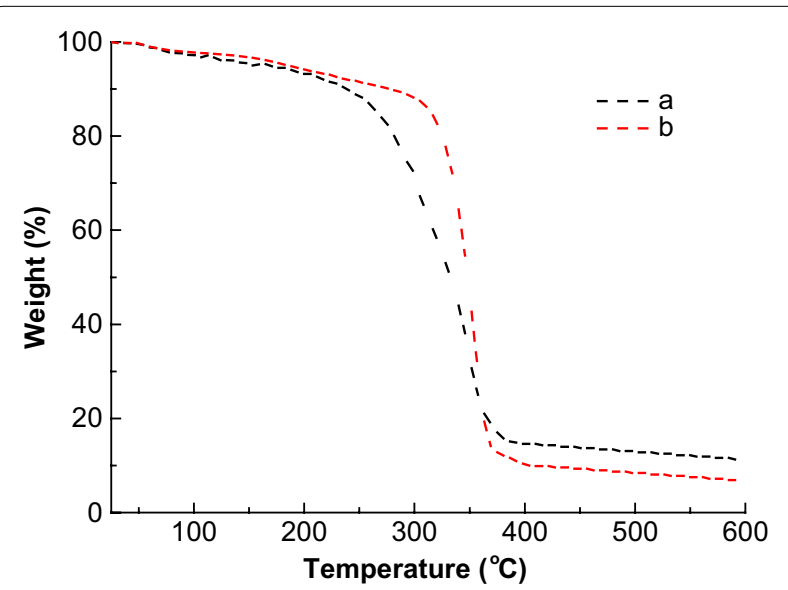

Fig. 3 TGA curves of the sugarcane bagasse (a) before and ( $b$ ) after the AGO pretreatment performed at $220^{\circ} \mathrm{C}$ for $2 \mathrm{~h}$ with a stirring speed of $150 \mathrm{rpm}$. The weight (\%) means the residual mass of the samples
AGO pretreatment, resulting in a relatively low residual content [24]. In short, due to the partial removal of hemicellulose, lignin, and other components, the AGOpretreated lignocellulosic biomass presented a high thermal stability and low ignition residue. It is confirmed that during the AGO pretreatment some main components, i.e., lignin and hemicellulose, indeed degraded/dissolved into the pretreatment liquor.

\section{SEM photos}

In order to understand the physical feature of AGOpretreated substrate, some morphological changes were determined with a series of comparative SEM observations. As seen in Additional file 1: Figure S1, the original sugarcane bagasse presented a smooth and contiguous surface with compact fiber bundles. After the AGO pretreatment, a significant size reduction occurred, and the long split fasciculus was exposed outside in an orderly manner. The long fibrils were loose and fine, which had a smaller average size with a more roughness and surface area. These images were agreeable with some recent reports $[25,26]$. The observation indicates that the pretreatment physically dissected the structural barrier of substrates and led to a large portion of long defibrillated fibrils with more surface area and roughness. Further, the more surface area and roughness enabled cellulase enzymes to access and attack the cellulose in defibrillated fibrils and hence an efficient enzymatic hydrolysis.

With the images enlarged, there were some irregular deposits that were noted on the uneven microfiber surface of pretreated substrates (Additional file 1: Figure S1c). However, the present observation was unclear and unsatisfactory, and further observations were necessary.

\section{AFM observation}

To clarify the unidentified deposits, some AFM images were further taken (see Additional file 1: Figure S2). The original sugarcane bagasse appeared flat and even with a relatively well-oriented fibrillar structure. After the pretreatment (Additional file 1: Figure S2c), there were some irregular granules and scraps inserted/dispersed on the uneven microfiber surface, forming an irregular deposit layer, which is consistent with the above SEM observation. Similar phenomena have been observed by our colleagues [27] and other researchers [25]. In our earlier work, some granules (0.1-0.2 um in diameter) and agglomerates (0.2-0.4 um in length) were observed with SEM and precipitated on the outer surface of AGO-pretreated wheat straw, which were inferred as a lignin scrap fraction and a polysaccharide fraction, respectively. They tended to form and migrate onto the outer surface of fibers during the pretreatment, owing to a lignin recondensation and/or lignin-carbohydrate complex (LCC) [27]. 
The formation and migration of spherical lignin deposits can expose more internal cellulose surface and probably provide more room in the substrate, allowing the entry of cellulase enzymes to the cellulose.

Three-dimensional images of the sugarcane bagasse were further taken (Additional file 1: Figure S2b, d). The root mean square (RMS) roughness $\left(\mathrm{R}_{\mathrm{q}}\right)$ was calculated from the topography images and recorded simultaneously with the phase images, as shown in Additional file 1: Table S1. The average roughness of sugarcane bagasse was $65.5 \mathrm{~nm}$, and it increased to $104.6 \mathrm{~nm}$ after AGO pretreatment. It can be judged that the roughness of substrate increased indeed after the pretreatment, though the value has fallen into a wide error margin due to the substrate heterogeneity and limited sample numbers. The high roughness of lignocellulosic substrate is acknowledged to facilitate the adsorption of cellulase enzyme and then expedite the enzymatic hydrolysis [22, 23].

\section{CLSM images}

Figure 4 illustrates CLSM images of the sugarcane bagasse (a) before and (b) after AGO pretreatment. In the original sugarcane bagasse, the lignin-rich sclerenchyma and middle lamella had an intact structure. The pretreatment resulted in a clear distortion of the whole structure at the tissue and organ levels. With a significant breakage of the microstructure of the plant cell wall, the sclerenchyma and middle lamella disintegrated, and also the primary and secondary cell walls separated from the middle lamella. These observations indicate that the AGO pretreatment has modified the recalcitrant architecture of native sugarcane bagasse, resulting in the tissue distortion, fibril swelling, and structure breakage, of which the loose fragmented structure is conducive to the enzymatic hydrolysis.

Based on the above morphological visualization, it has been demonstrated that the AGO pretreatment can indeed deconstruct the recalcitrant architecture of natural lignocellulosic biomass, with respect to the surface area, average size, component redistribution, and roughness. Moreover, it is speculated that the substrate modification is very probably due to a large dissociation of chemical bonds, especially some inter- and intramolecular hydrogen bonds responsible for the rigid and highly compact structure within biomass [23]. In order to test this, more features of sugarcane bagasse were probed at a supermolecular level.

\section{Mapping the supermolecular structure}

Structural change of sugarcane bagasse was detected with FT-IR spectroscopy in the region of $4000-400 \mathrm{~cm}^{-1}$ (Additional file 1: Figure S3). Consistent with the
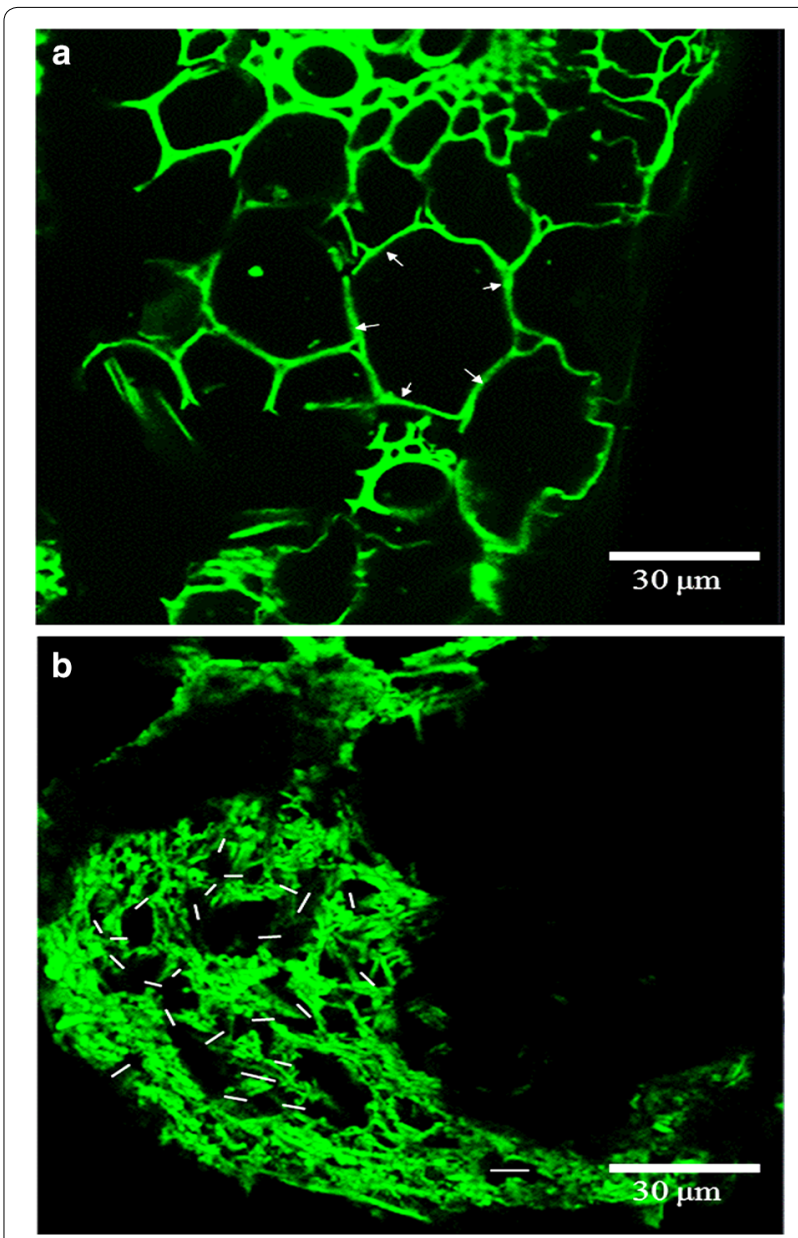

Fig. 4 CLSM images of the sugarcane bagasse (a) before and ( $\mathbf{b})$ after the AGO pretreatment performed at $220^{\circ} \mathrm{C}$ for $2 \mathrm{~h}$ with a stirring speed of $150 \mathrm{rpm}$. a White arrows point to the intact structure of lignin-rich sclerenchyma and middle lamella; b white short lines represent some chemical cuttings of the microstructure

delignification from sugarcane bagasse, the bands at $1324 \mathrm{~cm}^{-1}$ and the peak at $1168 \mathrm{~cm}^{-1}$ were all weakened. The peaks at $1604 \mathrm{~cm}, 1513$, and $833 \mathrm{~cm}^{-1}$ all disappeared from the AGO-pretreated sample [9]. The peak at $1240 \mathrm{~cm}^{-1}$, assigned to $\beta$-ether bond, almost diminished, indicating maximum dissociation of the lignin polymer bond. As for hemicellulose removal, the peak at $1737 \mathrm{~cm}^{-1}$, representing the characteristic of the uronic ester groups of hemicellulose or hemicellulose-lignin complexes, disappeared in AGO-pretreated substrates. The absorbance peak at $1375 \mathrm{~cm}^{-1}$ was due to partial acetylation of hydroxyl groups in both polysaccharides and residual lignin. With a relative increase of cellulose content in the pretreated substrate, the peak at $896 \mathrm{~cm}^{-1}$ associated with the presence of amorphous cellulose, $\beta$-glycosidic linkages, and $\mathrm{C} 1$ group vibration was intensified after the AGO pretreatment. An intensified 
signal at $1200 \mathrm{~cm}^{-1}$ was probably related to an increase of cellulose content. The band at $1105 \mathrm{~cm}^{-1}$ was intensified, indicating a relative increase of the crystalline cellulose. These results indicate that the AGO pretreatment has the capacity to break down some key chemical bonds and functional groups selectively in the supermolecular structure of sugarcane bagasse, thereby resulting in the most lignin and hemicellulose removal.

For the relative crystallinity, the absorbance ratio of $1378 / 2900 \mathrm{~cm}^{-1}$, representing the total crystallinity index, increased obviously from 0.88 to 1.02 after the pretreatment. Meanwhile, the absorbance ratio of $1437 / 899 \mathrm{~cm}^{-1}$, known as the crystallinity index or lateral order index, was basically stable before $(0.80)$ and after $(0.83)$ the pretreatment. Also, the absorbance ratio of $1089 / 899 \mathrm{~cm}^{-1}$ means that the ratio of amorphous to crystalline cellulose had no obvious change before (0.43) and after (0.47) AGO pretreatment. It can be presumed that the AGO pretreatment led to remarkable increases of both the amorphous and crystalline cellulose contents in substrates.

\section{Detection of fermentation inhibitors derived from the AGO pretreatment}

Numerous papers have indicated that some standing pretreatment methods-hot water [28], steam explosion [3], and organosolv pretreatment [12] - tend to produce some fermentation inhibitory compounds, such as FF and HMF. High inhibitor concentrations may severely hamper the performance of the fermenting microorganism and, in the worst case scenario, result in a non-fermentable hydrolysate. Because these inhibitory compounds have some potentially negative impacts on downstream microbial growth and biofuel production, it becomes one of the key case scenarios for a pretreatment technique to consider the formation of these by-products $[28,29]$. This experiment was purposed to detect the generation of two key fermentation inhibitors, furfural (FF) and 5-hydromethyl furfural (HMF), from the AGO pretreatment. As shown in Table 1, the yield of furan derivatives was significantly different owing to the variety of natural lignocellulosic feedstock and the diversification of the pretreatment process. The total yield was surprisingly low, at $<0.4 \mathrm{~g} / \mathrm{kg}$ lignocellulosic feedstock for the GOP pretreatment, whereas this was generally greater than $5.0 \mathrm{~g} / \mathrm{kg}$ for some leading pretreatment methods reported elsewhere. In this study, the FF and HMF content amounted to 0.30 and $0.07 \mathrm{~g}$ of each kilogram of sugarcane bagasse feedstock, respectively, which accounted for less than $10 \%$ of the low production reported to date from steam explosion and ethanol organosolv pretreatment $[12,29,30]$. In this regard, the AGO pretreatment can be even competitive to some alkali pretreatments is still competitive compared with alkali pretreatments (i.e., wet oxidation and AFEX) that are generally accepted as a low furan formation $(<2 \mathrm{~g}$ per kg lignocellulosic feedstock) [29]. A similar result was reported recently by Zhang et al. [31] on an atmospheric ethylene carbonate/ethylene glycol mixture pretreatment of sugarcane bagasse. They found that the content of xylose and furfural was very low in the pretreatment liquor, whereas no glucose and HMF were detected.

To understand the formation of these furan derivatives, xylose and glucose that almost equaled the corresponding release in the liquor from sugarcane bagasse were chosen as feedstock alternatives to implement the same AGO pretreatment and liquid hot water pretreatment,

Table 1 Detection of some key fermentation-inhibitive compounds (g/kg substrate) produced from the AGO pretreatment and other leading pretreatments

\begin{tabular}{|c|c|c|c|c|c|}
\hline \multirow[t]{2}{*}{ Substrate (1 kg) } & \multicolumn{2}{|l|}{ Pretreatment } & \multicolumn{2}{|c|}{ Pretreatment liquor } & \multirow[t]{2}{*}{ Source } \\
\hline & Method & Condition & $\mathrm{FF}(\mathrm{g})$ & HMF (g) & \\
\hline Miscanthus lutarioriparious & Liquid hot water & Pretreatment severity $=4.71$ & 9.9 & 3.6 & Li et al. [30] \\
\hline Corn stover & Dilute acid & / & $5-22$ & $0.9-30$ & van der Pol et al. [31] \\
\hline Corn stover & Steam explosion & $210^{\circ} \mathrm{C}, 5 \mathrm{~min}$ & 8.6 & 6 & Liu et al. [5] \\
\hline Poplar & Steam explosion & $210^{\circ} \mathrm{C}, 4 \mathrm{~min}$ & 4.9 & 0.8 & Oliva et al. [3] \\
\hline Poplar & $60 \%$ ethanol & $180{ }^{\circ} \mathrm{C}, 1 \mathrm{~h}, 1.25 \% \mathrm{H}_{2} \mathrm{SO}_{4}$ & 4.4 & 0.9 & Pan et al. [32] \\
\hline Agave bagasse & $50 \%$ ethanol & $160{ }^{\circ} \mathrm{C}, 10 \mathrm{~min}, 0.5 \% \mathrm{H}_{2} \mathrm{SO}_{4}$ & 5 & 3 & Caspeta et al. [12] \\
\hline Sugarcane bagasse & Glycerol & $220^{\circ} \mathrm{C}, 2 \mathrm{~h}$ & 0.3 & 0.07 & This study \\
\hline Xylose & Glycerol & $220^{\circ} \mathrm{C}, 2 \mathrm{~h}$ & 4.02 & 0.06 & This study \\
\hline Glucose & & & 0.94 & 6.9 & \\
\hline Xylose + glucose & & & 10.39 & 2.84 & \\
\hline Xylose + glucose & Liquid hot water & & 177.1 & 61.7 & \\
\hline
\end{tabular}

FF furfural, HMF 5-hydromethylfurfural 
respectively. For the liquid hot water pretreatment, the monosaccharide degradations were high, up to $177.1 \mathrm{~g}$ of FF and $61.7 \mathrm{~g}$ of HMF per kilogram of monosaccharide. In the glycerol system, the two inhibitors from the same amount of single or mixed monosaccharide yielded relatively low amounts. With one monosaccharide used as the lignocellulosic feedstock alternative, there was $4.0 \mathrm{~g}$ of FF from the xylose and $6.9 \mathrm{~g}$ of HMF from the glucose; $10.4 \mathrm{~g}$ of FF and $2.8 \mathrm{~g}$ of HMF were formed when these two monosaccharides were mixed together. Even though the yield from the monosaccharide was low, it was still tens times higher than that from the natural lignocellulosic feedstock (Table 1). The data indicate that the free monosaccharide was stable and did not tend to degrade into furan derivatives when suffering from the high temperature in the glycerol organosolv phase compared with the water phase. Apparently, it was not as easy to form sugar degradation products from the lignocellulosic biomass as from the monosaccharide. Alternatively, the glycerol organic solvent was probably involved in the degradation of hemicellulose/cellulose into the main oligosaccharides or xylosides/glucosides, other than the common monosaccharides formed during water-based (dilute acid, liquid hot water, and steam explosion) pretreatment [31]. The pure glycerol organic solvent can play a very prominent role in protecting monosaccharides against further degradation by the formation of xyloside/glucoside during the AGO pretreatment, thus inevitably contributing to a low furan derivative. This helps explain why extensively reported organosolv pretreatment has produced large fermentative inhibitors in the pretreatment liquor as the pretreatment solvent is mixed with high water content $(20-40 \%, v / v)[12]$. It can be deduced that sugar polymer and organic solvent phase are mainly responsible for the extraordinarily low formation of fermentation inhibitors from natural lignocellulosic biomass. In short, the AGO pretreatment can result in extremely low fermentation inhibitory products from natural lignocellulosic biomass, which are very helpful for the downstream enzymatic hydrolysis and microbial fermentation.

\section{Hydrolyzability of AGO-pretreated substrates}

The above result has demonstrated that the AGO-pretreated substrate is extremely susceptible and accessible to cellulase enzymes, inclusive of no significant inhibition. In this experiment, therefore, an impact of the AGO pretreatment on downstream enzymatic hydrolysis was initially investigated with regard to the benefit of a pretreatment method for biofuel production [4, 6]. Given that economical sugar production at a high concentration is typical of the enzyme-based biorefinery process, the enzymatic hydrolyzability of sugarcane bagasse undergoing the AGO pretreatment was assessed at a high substrate consistency with commercial cellulase preparation, Cellic $\mathrm{CTec} 2$, at a relatively low enzyme loading, as shown in Fig. 5. At $10 \mathrm{FPU} / \mathrm{g}$ dried substrate, all substrates presented a fast enzymatic hydrolysis, and the 72-h enzymatic hydrolysis of pretreated substrate at less than $15 \%$ solid concentration exceeded $90 \%$. At 6 FPU/g dried substrate, the 72-h enzymatic hydrolysis of substrates ( $\leq 12 \%$ consistency) was greater than $80 \%$. Compared with our recent report on AGO-pretreated wheat straw, the hydrolyzability of AGO-pretreated sugarcane bagasse was significantly good, which was probably due to the difference in cellulase preparation and lignocellulosic variety [21]. The hydrolyzability of AGO-pretreated substrate is outstanding compared with that from steam explosion [5] and AFEX [7]. These data demonstrate that the AGO pretreatment has enabled good hydrolyzability in sugarcane bagasse.

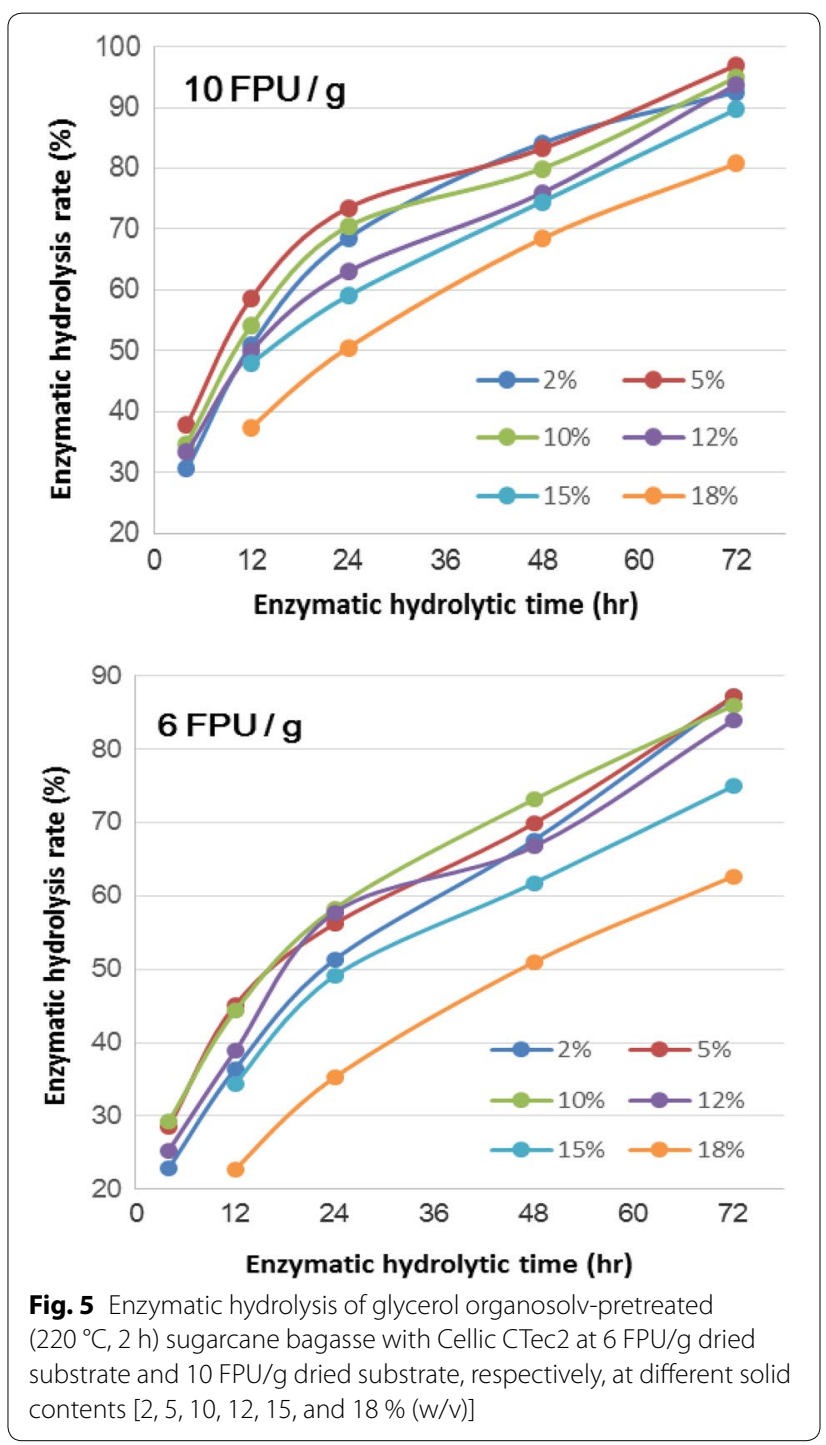


Interestingly, it is apparent that the new cellulase preparation Cellic CTec2 has a remarkable qualification in its toleration to high solid consistency. There is no significant adverse effect on the enzymatic hydrolysis of substrate until reaching $12 \%$ solid content, suggesting that the conventional substrate concentration ( $2 \%)$ is inapplicable to evaluate the hydrolyzability of a substrate or the efficiency of a new commercial cellulase preparation (e.g., Accellerase ${ }^{\circledR}$ DUET, Accellerase ${ }^{\circledR}$ TRIO $^{\mathrm{TM}}$ and Cellic CTec3) [6]. Moreover, the solid content of $5-10 \%$ is probably reasonable for the future industrially relevant evaluation.

\section{Fermentability of AGO-pretreated substrates}

The foregoing result on enzymatic hydrolysis has indicated that there is a significant inhibition of the enzymatic hydrolysis occurring at $>15 \%$ solid content, owing to the slurry's rheological property and sugar products' feedback effect [5]. Nevertheless, the high solid loadings $(\geq 15 \%)$ in the unit operations of lignocellulose conversion contribute to an increased sugar and ethanol concentration and thus a low production and capital cost [12]. Accordingly, the experiment was implemented to evaluate the fermentability of pretreated substrates at an initial $15 \%$ solid content by adopting SSF, Semi-SSF, and fed-batch semi-SSF. As shown in Fig. 6, with the SSF for $72 \mathrm{~h}$, the ethanol production from AGO-pretreated substrates was $27.0 \mathrm{~g} / \mathrm{L}$ at $10 \mathrm{FPU} / \mathrm{g}, 30.4 \mathrm{~g} / \mathrm{L}$ at $20 \mathrm{FPU} / \mathrm{g}$, and $33.0 \mathrm{~g} / \mathrm{L}$ at $30 \mathrm{FPU} / \mathrm{g}$ of cellulase enzyme loading, respectively. At 24-h fermentation, there was less than $1 \mathrm{~g} / \mathrm{L}$ of the glucose remaining in the fermentation broth (data not shown), indicating that low efficiency of the enzymatic hydrolysis probably hampered the ethanol fermentation. Accordingly, a 24-h prehydrolysis before the SSF-namely the semi-SSF-was adopted to strengthen the enzymatic hydrolysis. The $72-\mathrm{h}$ ethanol production reached $29.9 \mathrm{~g} / \mathrm{L}$ at $10 \mathrm{FPU} / \mathrm{g}, 32.7 \mathrm{~g} / \mathrm{L}$ at $20 \mathrm{FPU} / \mathrm{g}$, and $36.1 \mathrm{~g} / \mathrm{L}$ at $30 \mathrm{FPU} / \mathrm{g}$. Compared with the SSF, the ethanol production with the semi-SSF was enhanced by approximately $10 \%$. The result is unsatisfactory; a titer of $4 \%$ in the cellulosic ethanol fermentation broth is the minimum requirement for an economical distillation process. Based on the semi-SSF, one-third of the total dried pretreated substrate, together with the corresponding enzyme loading, was fed into the fermenter after 8,24 , and $36 \mathrm{~h}$ of fermentation, respectively, thus attaining a final equivalent content of $30 \%$ solid content. The results showed that the 72-h ethanol production achieved $45.4 \mathrm{~g} / \mathrm{L}$ at $10 \mathrm{FPU} / \mathrm{g}$, $49.3 \mathrm{~g} / \mathrm{L}$ at $20 \mathrm{FPU} / \mathrm{g}$, and $55.7 \mathrm{~g} / \mathrm{L}$ at $30 \mathrm{FPU} / \mathrm{g}$, each increasing 60-70\% compared with their respective initial SSF. The ethanol productivity (based on both enzymatic hydrolysis and fermentation) correspondingly reached $0.47,0.51$, and $0.58 \mathrm{~g} / \mathrm{L} / \mathrm{h}$. To date, there are very
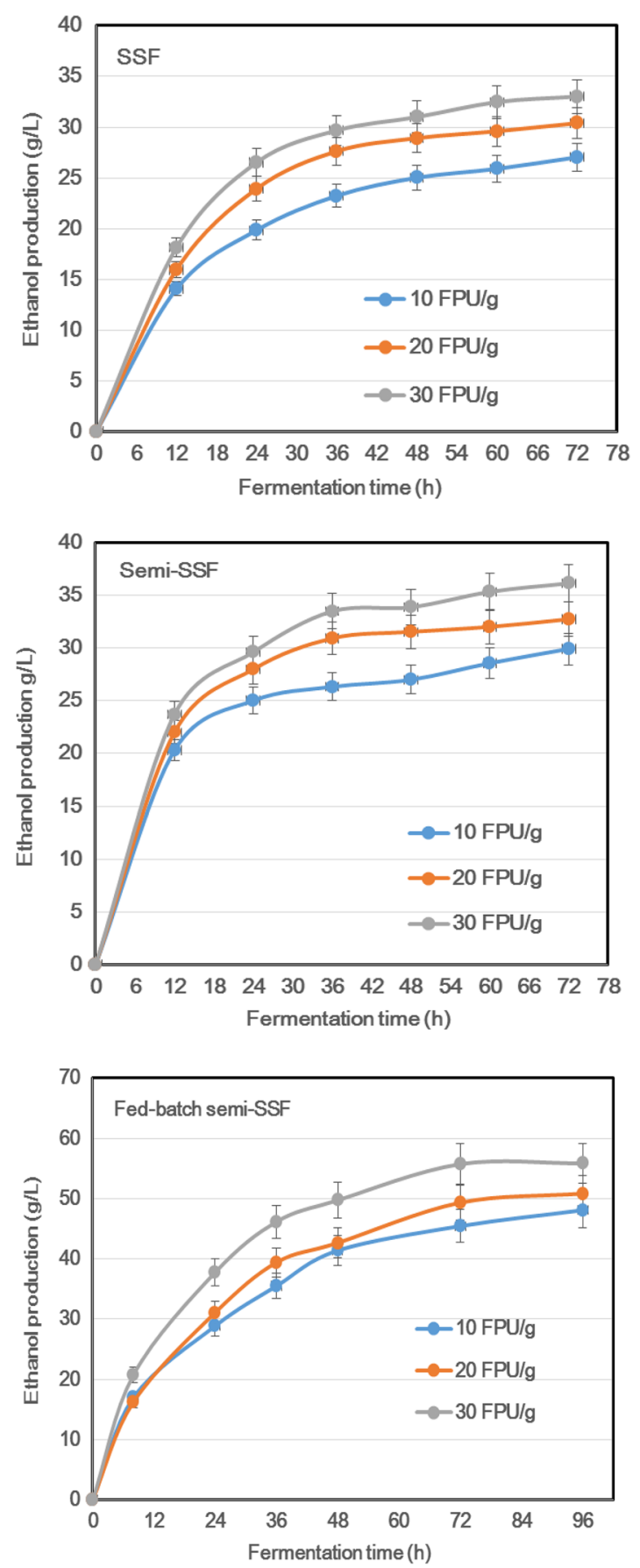

Fig. 6 Ethanol fermentation of glycerol organosolv-pretreated $\left(220^{\circ} \mathrm{C}, 2 \mathrm{~h}\right)$ sugarcane bagasse at an initial solid content of $15 \%$ $(\mathrm{w} / \mathrm{V})$. The enzyme loading of cellulase Cellic CTec2 was 10, 20, and $30 \mathrm{FPU} / \mathrm{g}$ dried substrate. For the SSF, the fermentation (initial pH 4.8, inoculation size $10 \%$, and shaking speed $120 \mathrm{r} / \mathrm{min}$ ) was carried out at $37^{\circ} \mathrm{C}$ for $72 \mathrm{~h}$. For the semi-SSF and fed-batch semi-SSF, the prehydrolysis was made at $50^{\circ} \mathrm{C}$ for $24 \mathrm{~h}$. For the fed-batch semi-SSF the other part of dried pretreated substrate (as much as total dried substrate used for the prehydrolysis) was divided into three aliquots and fed simultaneously with some corresponding cellulase enzymes into the fermenter after 8,24 , and $36 \mathrm{~h}$ of fermentation to ensure an equivalent $30 \%(\mathrm{w} / \mathrm{v})$ solid content 
few studies on $>50 \mathrm{~g} / \mathrm{L}$ of the bioethanol production and $>0.5 \mathrm{~g} / \mathrm{L} / \mathrm{h}$ of the productivity, although there are some good examples of ethanol yield ( $200 \pm 20 \mathrm{~g} / \mathrm{kg}$ feedstock) $[7,8,28]$. Consequently, the fermentability of AGO-pretreated lignocellulosic substrate is good and industrially relevant.

Additionally, a simple nutrient (only $10 \mathrm{~g} / \mathrm{L} \mathrm{NH}_{4} \mathrm{SO}_{4}$ ) was added into the fermentation slurry. The good fermentation performance of AGO-pretreated substrates is likely because the AGO pretreatment requires moderate washing steps, thereby preserving essential biomass nutrients for fermentation. The other reason is that the AGO pretreatment, like AFEX pretreatment, does not produce a highly inhibitory pretreatment mixture [7]. In short, the AGO pretreatment is promising as an efficient technology to convert plant-derived polysaccharides to bioethanol.

\section{Mass balance analysis}

The analysis presents an entire workflow based on the laboratory test of AGO pretreatment, enzymatic hydrolysis (@10 FPU/g with 15 \% solid content), and fed-batch
semi-SSF. As shown in Fig. 7, one kilogram of sugarcane bagasse was mixed with $14 \mathrm{~kg}$ of industrial glycerol and $6 \mathrm{~kg}$ of tap water in the cooker for the pretreatment. The water was evaporated and cooled at the temperatureelevating stage for recycling use. Actually, the glycerol in the AGO pretreatment liquor can be recycled almost ten times with simple precipitation and centrifugation. In the pretreatment liquor, most of the glucan surviving from the pretreatment existed in the form of glucose, apparently accounting for $2 / 3$ of the total cellulose loss. Strikingly, the xylan that split away from the undissolved solid existed in a very slight form of xylose $(<2 \%)$, predominantly the xylose polymers. This slight monosaccharide is responsible at least partly for the low inhibitory pretreatment mixture of FF and HMF. The AGO pretreatment was able to remove most of the lignin from sugarcane bagasse, generating a solid fraction enriched with glucan $(60.8 \%)$. The undissolved solid has outstanding enzymatic hydrolyzability, achieving $81.7 \%$ of the $72-\mathrm{h}$ glucan hydrolysis (@9\% glucan loading)with Cellic CTec2 at $15 \mathrm{FPU} / \mathrm{g}$ glucan. The final glucose content attained $82 \mathrm{~g} / \mathrm{L}$ in the hydrolysate. It can be envisioned that the

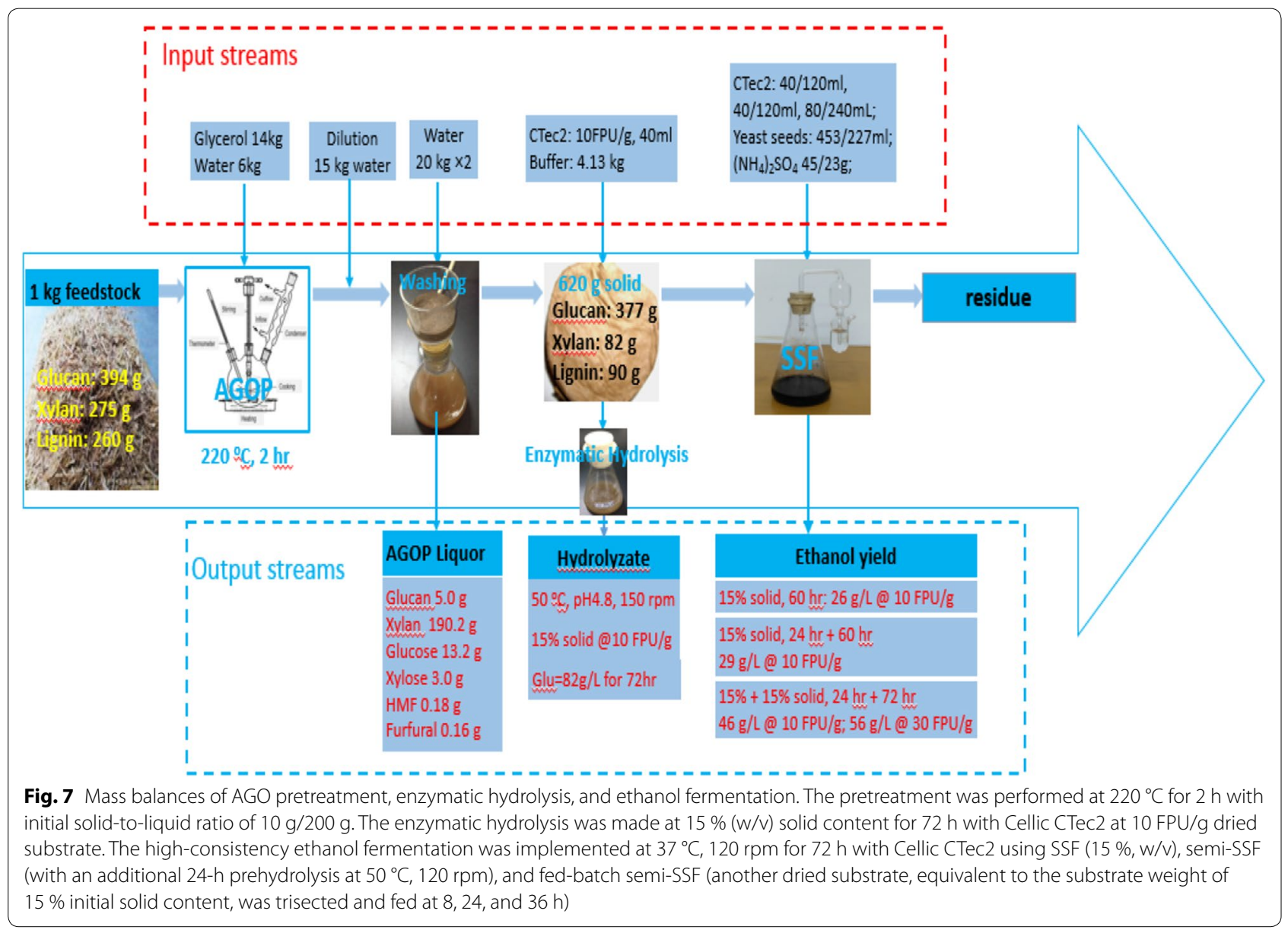


enzyme loading to complete the same enzymatic hydrolysis would be reduced to $5 \mathrm{FPU} / g$ glucan with an optimal use of some new cellulase enzyme preparations/cocktails (i.e., Cellic ${ }^{\circledR}$ CTec3, Cellic HTec3 and AA9) [33]. The good hydrolyzability of substrates enabled by the AGO pretreatment can contribute to an extremely significant step toward the more cost-effective commercial-scale production of cellulosic ethanol. Based on the highsolid-loading enzymatic hydrolysis, the fermentability of AGO-pretreated substrates was verified with an initial $15 \%$ solid content at 10 and $30 \mathrm{FPU} / \mathrm{g}$ dried substrate. The cellulosic ethanol yield was achieved approximately $50 \mathrm{~g} / \mathrm{L}$ using a fed-batch semi-SSF of the total $96 \mathrm{~h}$. In this scenario, the xylose derived from the hydrolysis of hemicellulose residual $(13.2 \%)$ in the pretreated substrate accumulated to almost $40 \mathrm{~g} / \mathrm{L}$ (data not shown) because the thermally tolerant alcohol yeast is not capable of consuming it. Therefore, it is necessary to consider the xylose-to-ethanol conversion in the future work for the economic production of cellulosic ethanol at a commercial scale [8]. Despite an interestingly high ethanol production $(\sim 50 \mathrm{~g} / \mathrm{L})$, the cellulose-to-ethanol conversion by fed-batch semi-SSF was still very low- $43.5 \%$ at $10 \mathrm{FPU} / \mathrm{g}$ and $53.4 \%$ at $30 \mathrm{FPU} / \mathrm{g}$. Unlike other standing pretreatment methods [4], the glycerol that is entrapped in the undissolved solid ( $<15 \%$ substrate weight) is likely to have a very low impact on the downstream enzymatic hydrolysis and microbial fermentation (30 \% solid content) because it is a natural carbon source of many microorganisms [24]. Accordingly, it can be assumed that the low ethanol conversion originates exclusively from the substandard enzymatic hydrolysis. In the future work, it is necessary to carry out considerable research to streamline the enzymatic hydrolysis process to make the bioethanol fermentation cost effective.

These results on the hydrolyzability and fermentability correlate well with the aforementioned physicochemical properties (compositional change and structural feature) of AGO-pretreated substrates. Based on the above analysis, it is evident that the glycerol organosolv pretreatment is promising for the current pretreatment. Additionally, this pretreatment process strategy is ideal for integration into a commercially successful lignocellulosic and vegetable oil biorefinery industry.

\section{Conclusions}

The AGO pretreatment has presented good selectivity on sugarcane bagasse. The pretreatment can contribute to an amazing physiochemical modification of lignocellulosic biomass towards superior susceptibility and accessibility to cellulase enzymes, with a high cellulose purity ( 60\%). Notably, there are extremely low amounts of fermentation-inhibitive compounds (i.e., $<0.40 \mathrm{~g} F \mathrm{~F}$ and $<0.10 \mathrm{~g}$
HMF $\mathrm{kg}^{-1}$ feedstock) generated in the pretreatment process. The undissolved solid has outstanding enzymatic hydrolyzability, achieving $90 \%$ of the 72 -h enzymatic hydrolysis at $15 \%$ solid content with Cellic CTec2 at $10 \mathrm{FPU} / \mathrm{g}$ dried substrate. With a simple nutrition (only $\left.10 \mathrm{~g} / \mathrm{L}\left(\mathrm{NH}_{4}\right)_{2} \mathrm{SO}_{4}\right)$ addition, the fed-batch semi-SSF of AGO-pretreated substrates reached almost $50 \mathrm{~g} / \mathrm{L}$ ethanol (30\% solid content) with the cellulase preparation at $10 \mathrm{FPU} / \mathrm{g}$ dried substrate. The AGO pretreatment is promising for the current pretreatment towards industrially relevant enzyme-based lignocellulosic biorefineries. Further improvements in overall ethanol yield and titer are required to increase the commercial attractiveness of this technology.

\section{Methods}

Materials

Sugarcane bagasse was obtained from Guangxi Province, China. It was dried to constant weight at $60{ }^{\circ} \mathrm{C}$ and then stored in a polyethylene plastic container. The main components of sugarcane bagasse were as follows: $39.4 \%$ glucan, $27.5 \%$ xylan, and $26.0 \%$ lignin. Industrial glycerol was of commercial grade ( $95 \%$ purity), purchased from a chemical plant in Jiangsu Province, China. It was diluted to $70 \%$ for use in the experiment. Cellulase Cellic CTec2 (150 FPU/g) was a generous gift from Novozymes (China) Investment Co. Ltd.

\section{AGO pretreatment process}

In a typical run, $10 \mathrm{~g}$ of dry sugarcane bagasse was directly mixed with $200 \mathrm{~g}$ of aqueous glycerol (70\% industrial glycerol) in a three-necked round-bottom flask as reported in our earlier work [14, 15]. A condenser was fitted in the right-hand neck of the flask for reflux, a thermocouple wire was passed through the left-hand neck to measure the temperature, and a stirrer was fitted into the middle neck of the flask to ensure full mixture stirring. The flask was heated at different combinations of temperature and time ranging from 200 to $240{ }^{\circ} \mathrm{C}$ for $1-5 \mathrm{~h}$. After heating to the desired temperature for the specified period of time, the mixture was allowed to cool to approximately $120{ }^{\circ} \mathrm{C}$. One hundred fifty grams of distilled water was then added. The mixture was stirred vigorously to ensure thorough disintegration. The insoluble solid fraction was then separated by filtration through a $G_{3}$ glass filter $(100 \mathrm{~mL}$, pore size $15-40 \mu \mathrm{m})$ and washed twice with $200 \mathrm{~g}$ of distilled water, and the insoluble solid fraction was divided into two parts. One part was conserved in a sealed bag at $5{ }^{\circ} \mathrm{C}$ for further enzymatic hydrolysis, and the other was dried at $60{ }^{\circ} \mathrm{C}$ to determine the pretreatment yield (the percentage of total solids recovered from the original feedstock), main components (the percentage of 
cellulose/hemicellulose/lignin in the insoluble solid fraction to that of the original feedstock), and structural change. The pretreatment liquor was collected to detect the main composition, including glucose, xylose, $\mathrm{FF}$, and HMF. In the experiment on AGO pretreatment, $0.40 \mathrm{~g}$ of glucose and $2.0 \mathrm{~g}$ of xylose were used alone and together, respectively, as an alternative to the $10 \mathrm{~g}$ of dry sugarcane bagasse under the same condition mentioned above. The liquid hot water treatment of $0.40 \mathrm{~g}$ of glucose and $2.0 \mathrm{~g}$ of xylose alone and together, respectively, was performed in a batch reactor (six-parallel acid digestion bomb of $200 \mathrm{~mL}$, SS 316 with Teflon liner) under the conditions mentioned above.

\section{Enzymatic hydrolysis of the resulting fiber fractions}

The wet solid substrate from the AGO pretreatment was put at different solid loadings into a $150-\mathrm{mL}$ flask and suspended quickly with $50 \mathrm{~mL}$ citrate buffer $(0.05 \mathrm{M}$, $\mathrm{pH} 4.8$ ) with an Cellic CTec2 loading of 10,20 , or 30 FPU/g dried substrate $[14,15]$. The experiment was performed at $150 \mathrm{rpm}$ in a rotary shaker at $50{ }^{\circ} \mathrm{C}$ for $72 \mathrm{~h}$, wherein samples were withdrawn at interval time and centrifuged at 10,000 rpm for $10 \mathrm{~min}$ to detect the total reducing sugar content. Enzymatic hydrolysis $(\%)=$ Total reducing sugars in the hydrolysate $(\mathrm{g}) \times 0.9 /[$ Cellulose (g) + Hemicellulose (g)] in substrates. Experiments with each sample were performed in duplicate, with the average value reported. The average relative standard deviation was below $3 \%$.

\section{Microorganism and seed culture preparation}

Angel ${ }^{\circledR}$ thermal tolerance alcohol active dry yeast (Angel Yeast Co., Ltd., Yichang, China) was used in this study [5, 28]. Seed cultures were prepared in a $150-\mathrm{ml}$ flask with $50 \mathrm{ml}$ of medium containing $(\mathrm{g} / \mathrm{L})$ yeast extract 5 , tryptone 5, glucose 50, $\mathrm{KH}_{2} \mathrm{PO}_{4} 1, \mathrm{MgSO}_{4} 0.3$, and $\mathrm{NH}_{4} \mathrm{Cl} 2$, at $37{ }^{\circ} \mathrm{C}$ and $120 \mathrm{rpm}$ for $12 \mathrm{~h}$. The seed liquid was then inoculated into the fermentation slurry at $10 \%(\mathrm{v} / \mathrm{v})$ of the inoculation size.

\section{Ethanol fermentation}

In the SSF, semi-SSF, and fed-batch semi-SSF, wet substrate from the undissolved solid fraction was used for the initial $15 \%$ solid content. The wet solid (7.50 g dry weight) was placed into a $250-\mathrm{mL}$ flask and suspended quickly with some citrate buffer $(0.05 \mathrm{M}, \mathrm{pH} 4.8)$ [including $0.5 \mathrm{~g}$ $\left.\left(\mathrm{NH}_{4}\right)_{2} \mathrm{SO}_{4}\right]$ to acquire $15 \%$ solid content $(\mathrm{w} / \mathrm{v})$. After the sterilization, the cellulase was added into the slurry at 10 , 20, or $30 \mathrm{FPU} / \mathrm{g}$ substrate. For the SSF, yeast seed liquid was added simultaneously with the cellulase preparation before the start of fermentation. For the semi-SSF, some cellulase preparations were first added into the slurry and hydrolyzed at $50{ }^{\circ} \mathrm{C}$ and $120 \mathrm{rpm}$ for $24 \mathrm{~h}$. The seed liquid was then inoculated in the broth after rapid cooling to $37^{\circ} \mathrm{C}$. For the fed-batch semi-SSF, the dried substrate (constant weight at $105{ }^{\circ} \mathrm{C}$ ), amounting to one-third of the initial total dried pretreated substrate, was fed at 8,24 , and $36 \mathrm{~h}$ of the semi-SSF time, together with the corresponding enzyme loading. All fermentation experiments were conducted at $37{ }^{\circ} \mathrm{C}$ for $72 \mathrm{~h}$ with a shaking speed of $120 \mathrm{rpm}$. Samples were taken at different time points and centrifuged at 10,000 rpm for $10 \mathrm{~min}$. Supernatants were filtered through a $0.22-\mu \mathrm{m}$ Whatman syringe filter. Compositions (glucose, xylose, and ethanol) of fermentation broth were determined by HPLC $[5,28]$. All of these experiments were conducted with two replicates.

\section{Structural characterization}

A series of analytical techniques were employed as reported recently by us [21]. Thermal stability of the sample was analyzed using thermogravimetric analysis (TGA-STDA851e, Mettler-Toledo, Switzerland). Morphological Changes were observed with a scanning electron microscope (SEM), Quznfa-200 (FEI, Netherlands), an atomic force microscope (AFM), and a confocal laser scanning microscope (CLSM), LSM 710 (Zeiss, Germany). FT-IR spectra of the samples were recorded on an FT-IR spectrophotometer (NICOLET NEXUS 470, Thermo Nicolet, US) from finely ground samples (1\%) in $\mathrm{KBr}$ pellets in the range of $4000-400 \mathrm{~cm}^{-1}$.

\section{Analytical procedures}

The total reducing sugar content was determined by the standard 3,5-dinitrosalicylic acid method [33]. The main component (cellulose, hemicellulose, and lignin content) was determined by the two-step acid hydrolysis method (NREL) [34]. The wavelength of $240 \mathrm{~nm}$ was used for the determination of acid-soluble lignin. A muffle furnace was used at approximately $600{ }^{\circ} \mathrm{C}$ to indirectly measure the acid-insoluble lignin. The Chromaster HITACHI HPLC system equipped with an Aminex HPX-87H column $(300 \times 7.8 \mathrm{~mm}$, BioRad, US) was used at the column temperature of $65^{\circ} \mathrm{C}$, with $5 \mathrm{mM} \mathrm{H}_{2} \mathrm{SO}_{4}$ as the mobile phase at a flow rate of $0.6 \mathrm{~mL} \mathrm{~min}{ }^{-1}$ to detect the monosaccharides, ethanol, and sugar degradation products (FF and HMF). A refractive index detector (RID) and a diode array detector (DAD) were used in series. The RID was used to measure the monosaccharides (glucose, xylose, and arabinose) and ethanol. The DAD was used to detect the key sugar degradation products (FF and HMF) with a detection wavelength of $280 \mathrm{~nm}$. The entire analytical determination was performed in duplicate. The average relative standard deviation was below $6 \%$. 


\section{Additional file}

Additional file 1: Table S1. The substrate roughness measured from AFM images. Figure S1. SEM images of the sugarcane bagasse before and after the AGO pretreatment. Figure S2. AFM images of the sugarcane bagasse before and after the AGO pretreatment. Figure S3. FT-IR spectra of the sugarcane bagasse before and after the AGO pretreatment.

\section{Abbreviations}

AGO: atmospheric glycerol organosolv; SF: simultaneous saccharification and fermentation; semi-SSF: SSF with prehydrolysis; AFEX: ammonia fiber explosion; SPORL: sulfite pretreatment to overcome recalcitrance of lignocellulose; FF: furfural; HMF: 5-hydromethyl furfural; SEM: scanning electron microscopy; AFM: atomic force microscopy; CLSM: confocal laser scanning microscopy; TGA: thermogravimetric analysis; FT-IR: Fourier transform infrared spectroscopy; FPU: filter paper unit; LCC: lignin-carbohydrate complex; Crl: crystallinity index; RMS: root mean square.

\section{Authors' contributions}

FFS designed the project, supervised the experiments, interpreted the data, and prepared the manuscript. $X Z, J H$, and $X \mathrm{~L}$ conducted the experiment on hydrolyzability and fermentability. LW and YT carried out the pretreatment and structural feature section. HS and JHu contributed to the experimental design and helped polish it. All authors read and approved the final manuscript.

\section{Author details}

${ }^{1}$ Key Laboratory of Industrial Biotechnology, School of Biotechnology, Ministry of Education, Jiangnan University, Wuxi 214122, China. ${ }^{2}$ State Key Laboratory of Pulp and Paper Engineering, South China University of Technology, Guangzhou 510640, China. ${ }^{3}$ Key Laboratory of Advanced Textile Materials and Manufacturing Technology, Ministry of Education, Zhejiang Sci-Tech University, Hangzhou 310018, China. ${ }^{4}$ State Key Laboratory of Motor Vehicle Biofuel Technology, Henan Tianguan Group Co., Ltd, Nanyang 473000, China. ${ }^{5}$ Institute of Tropical Bioscience and Biotechnology, Chinese Academy of Tropical Agricultural Sciences, Haikou 571101, China. ${ }^{6}$ Forestry Products Biotechnology/Bioenergy Group, Wood Science Department, University of British Columbia, 2424 Main Mall, Vancouver, BC V6T 1Z4, Canada.

\section{Acknowledgements}

The work was funded by the National Natural Science Foundation of China (21176106), the Fundamental Research Funds for the Central Universities (JUSRP51635B; JUSRP51510), the National Nonprofit Institute Research Grant of CATAS-ITBB (2015RC06), and the China Postdoctoral Science Foundation (2015M571666). Part of the work was also supported by Opening Projects of State Key Laboratory of Motor Vehicle Biofuel Technology (KFKT2013010), State Key Laboratory of Pulp and Paper Engineering (201513), and Key Laboratory of Advanced Textile Materials and Manufacturing Technology (2015002). The authors would also like to give thanks to the Priority Academic Program Development of Jiangsu Higher Education Institutions, the 111 Project (No. 111-2-06), and the Jiangsu province "Collaborative Innovation Center for Advanced Industrial Fermentation" industry development program.

\section{Competing interests}

The authors declare that they have no competing interests.

Received: 10 January 2016 Accepted: 23 February 2016 Published online: 11 March 2016

\section{References}

1. Rubin EM. Genomics of cellulosic biofuels. Nature. 2008;454:841-5.

2. Himmel ME, Ding S-Y, Johnson DK, Adney WS, Nimlos MR, Brady JW, Foust TD. Biomass recalcitrance: engineering plants and enzymes for biofuels production. Science. 2007:315:804-7.

3. Oliva JM, Sáez F, Ballesteros I, González A, Negro MJ, Manzanares P, Ballesteros M. Effect of lignocellulosic degradation compounds from steam explosion pretreatment on ethanol fermentation by thermotolerant yeast Kluyveromyces marxianus. Appl Biochem Biotechnol. 2003;105-108:141-53.

4. Ouellet M, Datta S, Dibble DC, Tamrakar PR, Benke PI, Li C, Singh S, Sale KL, Adams PD, Keasling JD. Impact of ionic liquid pretreated plant biomass on Saccharomyces cerevisiae growth and biofuel production. Green Chem. 2011:13:2743-9.

5. Liu Z-H, Qin L, Zhu J-Q, Li B-Z, Yuan Y-J. Simultaneous saccharification and fermentation of steam-exploded corn stover at high glucan loading and high temperature. Biotechnol Biofuels. 2014; 7.

6. Wang ZJ, Lan TQ, Zhu JY. Lignosulfonate and elevated $\mathrm{pH}$ can enhance enzymatic saccharification of lignocelluloses. Biotechnol Biofuels. 2013; 6 .

7. Uppugundla N, da Costa Sousa L, Chundawat SP, Yu X, Simmons B, Singh S, Gao X, Kumar R, Wyman CE, Dale BE. A comparative study of ethanol production using dilute acid, ionic liquid and AFEX ${ }^{\mathrm{TM}}$ pretreated corn stover. Biotechnol Biofuels. 2014;7:72.

8. Jin M, da Costa Sousa L, Schwartz C, He Y, Sarks C, Gunawan C, Balan V, Dale BE. Toward lower cost cellulosic biofuel production using ammonia based pretreatment technologies. Green Chem. 2016. doi:10.1039/c5gc02433a.

9. Zhao X, Cheng K, Liu D. Organosolv pretreatment of lignocellulosic biomass for enzymatic hydrolysis. Appl Microbiol Biotechnol. 2009:82:815-27.

10. Hallac BB, Sannigrahi P, Pu Y, Ray M, Murphy RJ, Ragauskas AJ. Effect of ethanol organosolv pretreatment on enzymatic hydrolysis of Buddleja davidii stem biomass. Ind Eng Chem Res. 2010;49:1467-72.

11. Sannigrahi P, Miller SJ, Ragauskas AJ. Effects of organosolv pretreatment and enzymatic hydrolysis on cellulose structure and crystallinity in Loblolly pine. Carbohydr Res. 2010;345:965-70.

12. Caspeta L, Caro-Bermúdez MA, Ponce-Noyola T, Martinez A. Enzymatic hydrolysis at high-solids loadings for the conversion of agave bagasse to fuel ethanol. Appl Energy. 2014;113:277-86.

13. Yang F, Hanna MA, Sun R. Value-added uses for crude glycerol-a byproduct of biodiesel production. Biotechnol Biofuels. 2012:5.

14. Sun F, Chen $\mathrm{H}$. Evaluation of enzymatic hydrolysis of wheat straw pretreated by atmospheric glycerol autocatalysis. J Chem Technol Biotechnol. 2007;82:1039-44.

15. Sun $\mathrm{F}$, Chen $\mathrm{H}$. Enhanced enzymatic hydrolysis of wheat straw by aqueous glycerol pretreatment. Bioresour Technol. 2008;99:6156-61.

16. Martín C, Puls J, Saake B, Schreiber A. Effect of glycerol pretreatment on component recovery and enzymatic hydrolysis of sugarcane bagasse. Cell Chem Technol. 2011:45:487-94.

17. Novo LP, Gurgel LVA, Marabezi K, da Silva Curvelo AA. Delignification of sugarcane bagasse using glycerol-water mixtures to produce pulps for saccharification. Bioresour Technol. 2011;102:10040-6.

18. Zhang Z, O'Hara IM, Doherty WO. Pretreatment of sugarcane bagasse by acidified aqueous polyol solutions. Cellulose. 2013;20:3179-90.

19. Romaní $A$, Ruiz HcA, Pereira FB, Domingues $L$, Teixeira JA. Fractionation of Eucalyptus globulus wood by glycerol-water pretreatment: optimization and modeling. Ind Eng Chem Res. 2013;52:14342-52.

20. Hundt M, Schnitzlein K, Schnitzlein MG. Alkaline polyol pulping and enzymatic hydrolysis of hardwood: effect of pulping severity and pulp composition on cellulase activity and overall sugar yield. Bioresour Technol. 2013:136:672-9.

21. Sun FF, Wang L, Hong J, Ren J, Du F, Hu J, Zhang Z, Zhou B. The impact of glycerol organosolv pretreatment on the chemistry and enzymatic hydrolyzability of wheat straw. Bioresour Technol. 2015;187:354-61.

22. Chundawat SPS, Donohoe BS, da Costa Sousa L, Elder T, Agarwal UP, Lu F, Ralph J, Himmel ME, Balan V, Dale BE. Multi-scale visualization and characterization of lignocellulosic plant cell wall deconstruction during thermochemical pretreatment. Energy Environ Sci. 2011:4:973-84.

23. Ding SY, Liu YS, Zeng Y, Himmel ME, Baker JO, Bayer EA. How does plant cell wall nanoscale architecture correlate with enzymatic digestibility? Science. 2012;338:1055-60.

24. Lan W, Liu C-F, Yue F-X, Sun R-C, Kennedy JF. Ultrasound-assisted dissolution of cellulose in ionic liquid. Carbohyd polym. 2011;86:672-7.

25. Zhang Z, Wong HH, Albertson PL, Doherty WO, O'Hara IM. Laboratory and pilot scale pretreatment of sugarcane bagasse by acidified aqueous glycerol solutions. Bioresource Technol. 2013;138:14-21.

26. Harrison MD, Zhang Z, Shand K, O'Hara IM, Doherty WO, Dale JL. Effect of pretreatment on saccharification of sugarcane bagasse by complex and simple enzyme mixtures. Bioresource Technol. 2013:148:105-13. 
27. Sun F, Chen H. Organosolv pretreatment by crude glycerol from oleochemicals industry for enzymatic hydrolysis of wheat straw. Bioresource technol. 2008:99:5474-9.

28. Li HQ, Li CL, Sang T, Xu J. Pretreatment on Miscanthus /utarioriparious by liquid hot water for efficient ethanol production. Biotechnol Biofuels. 2013;6:76.

29. van der Pol EC, Bakker RR, Baets P, Eggink G. By-products resulting from lignocellulose pretreatment and their inhibitory effect on fermentations for (bio) chemicals and fuels. Appl Microbiol Biotechnol. 2014;98:9579-93.

30. Pan X, Gilkes N, Kadla J, Pye K, Saka S, Gregg D, Ehara K, Xie D, Lam D, Saddler J. Bioconversion of hybrid poplar to ethanol and co-products using an organosolv fractionation process: optimization of process yields. Biotechnol Bioeng. 2006;94:851-61.
31. Zhang Z, O'Hara IM, Rackemann DW, Doherty WO. Low temperature pretreatment of sugarcane bagasse at atmospheric pressure using mixtures of ethylene carbonate and ethylene glycol. Green Chem. 2013;15:255-64.

32. Sun FF, Hong J, Hu J, Saddler JN, Fang X, Zhang Z, Shen S. Accessory enzymes influence cellulase hydrolysis of the model substrate and the realistic lignocellulosic biomass. Enzyme Microb Tech. 2015;79:42-8.

33. Miller GL. Use of dinitrosalicylic acid reagent for determination of reducing sugar. Anal Chem. 1959;31:426-8.

34. Sluiter A, Hames B, Ruiz R, Scarlata C, Sluiter J, Templeton D, Crocker D. Carbohydrates and lignin in Biomass Laboratory Analytical Procedure (LAP). In:Tech Rep NREL/TP-510-42618; 2008.

\section{Submit your next manuscript to BioMed Central and we will help you at every step:}

- We accept pre-submission inquiries

- Our selector tool helps you to find the most relevant journal

- We provide round the clock customer support

- Convenient online submission

- Thorough peer review

- Inclusion in PubMed and all major indexing services

- Maximum visibility for your research

Submit your manuscript at www.biomedcentral.com/submit
(O) Biomed Central 